\title{
O CONCEITO DE FORMAÇÃO DISCURSIVA A PARTIR DOS ESTUDOS DE DOMINIQUE MAINGUENEAU E MICHEL FOUCAULT: UMA ANÁLISE COMPARATIVA
}

\section{DANTE AUGUSTO ASSIS RIBEIRO DE FREITAS*}

Universidade de São Paulo (USP), Programa de Pós-Graduação em Filologia e Língua Portuguesa (DCLV-FLP/FFLCH), São Paulo, SP, Brasil.

Recebido em: 28 ago. 2019. Aprovado em: 10 fev. 2021.

Como citar este artigo: FREITAS, D. A. A. R. de. 0 conceito de formação discursiva a partir dos estudos de Dominique Maingueneau e Michel Foucault: uma análise comparativa. Cadernos de Pós-Graduação em Letras, v. 21, n. 1, p. 230-247, jan./abr. 2021. doi: 10.5935/cadernosletras.v21n1p230-247

\section{Resumo}

Conceber a relação entre língua e discurso como mediadores das relações sociais do homem requer um olhar sobre a maneira como tais pressupostos, isto é, a interação entre os indivíduos com a língua e a exterioridade, veiculam significados no contexto sócio-histórico. Sendo assim, este artigo objetiva analisar e compreender, comparativamente, como o entendimento de formação discursiva está postulado em Michel Foucault (2016) e Dominique Maingueneau (2008, 2015). O intuito deste trabalho não é, em hipótese alguma, sobrepor um conceito ao outro, mas estabelecer uma interlocução entre os dois estudiosos,

* E-mail: danteaugusto01@gmail.com

(D) https://orcid.org/0000-0003-4272-9871 
situados em contextos diferentes, mas com a mesma preocupação: os estudos discursivos.

\section{Palavras-chave}

Foucault. Formação discursiva. Maingueneau.

\section{INTRODUÇÃO: PRELIMIINARES SOBRE O ESTUDO DAS FORMAÇÕES DISCURSIVAS}

Por tratar-se de uma unidade de análise para a análise do discurso (doravante $\mathrm{AD}$ ) de linha francesa, a noção de formação discursiva (doravante FD) apresenta diferentes concepções, dependendo da maneira como se olha determinado fenômeno da linguagem. Isso significa afirmar que a forma como o conceito de FD é compreendido pode fazer emergir significados que se expandem e se confluem. Contudo, no presente trabalho, pretendemos discutir a noção de FD sob a ótica de Foucault (2016) e Maingueneau (2008, 2015), que apresentam conceitos que ora se intercruzam, ora se distanciam. Ansiamos por levantar um questionamento sobre como os referidos autores discorrem sobre a noção de FD, empreendendo, dessa forma, uma relação de contiguidade no que diz respeito ao conceito de FD. Não obstante, isso não ocorre devido ao fato de estarem inseridos em campos epistemológicos e contextos sócio-históricos diferentes, mas ainda por serem compreendidos, na unidade das ciências humanas, em arenas de significação diferenciadas.

Nosso objetivo é realizar um entrecruzamento de ideias sobre o conceito de FD, partindo do pressuposto de que tal conceito não é meramente ordinário e nem pouco fecundo, pois advém de relações entre a filosofia e os estudos da linguagem. Desse modo, a compreensão sobre as FDs é fundamental para se entender a arena de significações entre a AD de linha francesa e os estudos arqueológicos da filosofia foucaultiana.

Dessa forma, "é preciso construir uma concepção sobre o objeto" (COLOMBAT; FOURNIER; PUECH, 2017, p. 16) que delimite, em certa medida, as arenas de significação que servirão de aporte para esse estudo. Contudo, conceituar as FDs como categorias analíticas requer recuperar a jurisdição na qual elas se orientam e organizam: o discurso. É por meio dele que elas 
se constituem e se ressignificam, uma vez que "não há interesse epistemológico que parta do fato do discurso sem que, previamente, este (o discurso) tenha como experiência social" (MAINGUENEAU, 1997, p. 33-34). O discurso, nesse sentido, extrapola os limites puramente linguísticos da língua e se instaura na instância da enunciação. Com isso, a discursividade percorre as FDs e os sujeitos que são interpelados pela experiência social, determinando, por isso, os ditos e não ditos. O discurso não é um corpo que se adquire, uma matéria que se pode ou não adquirir. É um acontecimento, uma ação.

\section{As formações discursivas}

Muitos autores, como Foucault (2016), Courtine (2014), Maingueneau (2008, 2015), Baronas (2020), Voss dos Santos (2020), Araújo (2020) e Indursky (2020), já discorreram sobre o conceito de FD, oferecendo à comunidade acadêmica uma gama de possibilidade para se estudar esse fenômeno da linguagem. Segundo Charaudeau e Maingueneau (2008), o primeiro a postular o conceito de FD foi Michel Foucault, e depois Pêcheux o reformulou para que fosse enquadrado ao universo da linguagem, à $\mathrm{AD}$ propriamente dita.

Sob influência do marxismo althusseriano, Pêcheux formulou que as formações sociais são sempre instauradas por lutas de classe, isto é, indivíduos ideologicamente marcados pela presença de "posições políticas e ideológicas, que não são feitas de indivíduos, mas que se organizam em formações que mantêm em si relações de antagonismo, de aliança ou dominação" (CHARAUDEAU; MAINGUENEAU, 2008, p. 241, grifo dos autores). E no que diz respeito a essas formações, elas podem ser categorizadas como uma unidade ou uma gama de FDs, determinando "o que pode e deve ser dito" (HAROCHE; HENRY; PÊCHEUX, 1971, p. 102 apud CHARAUDEAU; MAINGUENEAU, 2008, p. 241, grifo dos autores).

A partir dessas premissas, os sujeitos não possuem liberdade para "enunciar” sem que estejam condicionados às forças das formações ideológicas (doravante FI) e FDs. É nelas que ocorrem o interpelamento e assujeitamento do sujeito, no entanto, o próprio Pêcheux revê seu posicionamento na década de 1970, pois passa a conceber o interdiscurso como construtor de sentidos e pertencente às FDs e às FIs. Com o primado do interdiscurso, nas palavras de Pêcheux (apud CHARAUDEAU; MAINGUENEAU, 2008, p. 287), “a forma- 
ção discursiva não pode produzir o assujeitamento ideológico do sujeito do discurso a não ser em que cada formação discursiva está de fato dominada pelo interdiscurso ${ }^{1}[. .$.$] ". Dessa forma, para Pêcheux (1983, p. 297$ apud CHARAUDEAU; MAINGUENEAU, 2008, p. 241):

\begin{abstract}
Uma formação discursiva não é um espaço estrutural fechado, já que ela é constitutivamente "invadida" por elementos provenientes de outros lugares, i.e., de outras formações discursivas, que nelas se repetem fornecendo-lhe suas evidências discursivas fundamentais (por exemplo sob a forma de 'pré-construídos') e de discursos 'transversos'.
\end{abstract}

A respeito do pré-construído dentro de uma FD, trata-se, segundo Courtine (2014, p. 74), de "uma construção anterior, exterior, independente por oposição ao que é construído na enunciação. Ele marca a existência de um descompasso entre o interdiscurso, como lugar de enunciação por um sujeito". Isso significa afirmar que o pré-construído para a $\mathrm{AD}$ associa-se ao assujeitamento do que pode ou não ser dito em uma dada situação enunciativa. Ele evoca um entendimento que diz que o sentido se dá sob a forma de universalidade, em outras palavras, ideologicamente. Assim, para discorrer sobre sentido:

Falar-se-á de formação ideológica para caracterizar um elemento (determinado na luta dos aparelhos) suscetível de intervir como força confrontada com outras na conjuntura ideológica característica de uma formação social em um momento dado; cada formação ideológica constitui assim um complexo de atitudes de representações que não são nem "individuais" nem "universais", mas se relacionam mais ou menos diretamente a posições de classe de conflito umas em relações às outras (HAROCHI et al, 1971, p. 102 apud BRANDÃO, 1994, p. 38).

Essa afirmação nos diz que a luta ideológica das formações está estritamente relacionada a embates sócio-históricos conflituosos de posicionamento de uma certa ideia, de uma acepção a um dado tema e que os indivíduos que dela fazem parte estão interpostos coletivamente, fazendo emergir suas posi-

1 Entendido como um conjunto de discursos (de um mesmo campo discursivo ou de campos distintos) que mantêm relação recíproca uns com os outros (CHARAUDEAU; MAINGUENEAU, 2008, p. 286). O interdiscurso também foi conceituado como uma articulação contraditória de FDs que se referem a formações ideológicas antagônicas (COURTINE, 1981 apud CHARAUDEAU; MAINGUENEAU, 2008, p. 286). 
ções em um dado contexto discursivo. Ainda em Brandão (1994, p. 38): "Pode-se afirmar que uma formação ideológica tem necessariamente uma ou várias formações discursivas interligadas porque os discursos são interligados por formações ideológicas".

Ainda para a autora, o funcionamento de uma FD ocorre de duas formas. Os sentidos advindos dos discursos não estão soltos sem um aparato funcional de regularidades. Apesar de parecerem "soltos" e suscetíveis a quaisquer tipos de interpretação, eles fazem parte do jogo de enunciação que delimita o que se irá apreender, e é nesse contexto que Orlandi (2009) discorre sobre as FDs, baseando-se nos estudos de Pêcheux.

Para a referida autora, tal conceito instaura-se em um certo momento histórico, de modo a delimitar o que se pode ou não dizer. De acordo com Orlandi (2009), a produção de sentidos depende desses postulados, e os discursos, até certo ponto, emergem seus sentidos à medida que estão relacionados aos pressupostos ideológicos. As palavras, segundo a autora, estão carregadas de construtos ideológicos e se é tal, as FDs, nas quais as palavras estão inscritas, também o são.

Dessa maneira, os significados/sentidos são ideologicamente marcados e não estão "na essência das palavras, mas na discursividade, isto é, na maneira como, no discurso, a ideologia produz seus efeitos, materializando-se nele" (ORLANDI, 2009, p. 43).É por meio das FDs que os sentidos são transmitidos e assimilados porque se inscrevem em outras FDs. As palavras assumem significações distintas porque o caráter polissêmico está presente nos postulados da teoria do discurso além da metáfora, ${ }^{2}$ que se diferencia do conceito que atualmente é empregado pela ciência da linguagem.

\section{A FORMAÇÃO DISCURSIVA EM FOUCAULT}

A noção de FD em Foucault não se assemelha inteiramente com aquelas apresentadas até o presente momento. Tal conceito surgiu, primeiramente, em seu livro A arqueologia do saber, cuja publicação se deu em 1969. Obra esta

2 Para a autora, a noção de metáfora, pela primeira vez mencionada neste estudo, assume suma importância para os estudos discursivos. Para Orlandi (2009, p. 44), ela não é considerada, como na retórica, como figura de linguagem. A metáfora (cf. LACAN, 1966) é aqui definida como a tomada de uma palavra pela outra. $\mathrm{Na} \mathrm{AD}$, ela significa basicamente "transferência", estabelecendo o modo como as palavras significam. 
que servirá de aporte teórico principal para as discussões que se pretendem neste trabalho. Dessa forma, é preciso, de antemão, compreender que se trata não de um apanhado de conceitos a serem apreendidos, mas de procedimentos a serem adotados na esfera das unidades dos estudos discursivos.

A arqueologia não preconiza a produção de marcos históricos, mas é um método para se saber em que momento um referido conceito tornou-se uma verdade. É nesse ínterim que o autor se interroga sobre a arqueologia que visa à detecção dos discursos e à formação histórica de determinado campo do saber. Para realizar tal feito, Foucault se fez valer de quatro hipóteses para conceituar o seu entendimento sobre FD.

Foucault (2016) nos diz acerca do emprego dos conceitos de descontinuidade, de ruptura, de limiar, de limite, de série, de transformação; coloca, em qualquer análise histórica, questões de procedimento, mas também problemas teóricos. Distanciando-se das teorias que tentam emaranhar de maneira conjunta e sistematizada a compreensão dos conceitos, Foucault pergunta-se qual foi o processo que transformou aquilo em um fato de verdade.

A partir dessas premissas, ele compreende, em sua primeira hipótese, que os enunciados estão dispersos no tempo e que não estão propriamente relacionados às questões da língua, mas a determinado correlato de dispersões e continuidades, descontinuidades, causando, então, para a linearidade dos estudos históricos, uma disparidade. Tal fundamentação adquire corpo quando o empreendimento metodológico se constitui na predileção pelo objeto. Sobre isso, Foucault (2016, p. 39) assinala que "os enunciados diferentes em sua forma, dispersos no tempo, formam um conjunto quando se referem a um único e mesmo objeto". E reitera:

[...] definir um conjunto de enunciados no que eles têm de individual consistiria em descrever a dispersão desses objetos, aprender os interstícios que os separam, medir as distâncias que reinam sobre eles, em outras palavras formular sua lei de repartição (FOUCAULT, 2016, p. 40-41).

Como exemplo da relação entre os objetos e os enunciados, o autor faz uso do objeto da loucura que "não permite individualizar um conjunto de enunciados pertinentes à psicopatologia, mas referem-se a esse objeto que se perfila de diferentes maneiras, na experiência individual ou social e que pode se designar por loucura" (FOUCAULT, 2016, p. 39). Não obstante, conduz a discussão dizendo ainda que 
[...] esse conjunto de enunciados está longe de relacionar com um único objeto, formado de maneira definitiva, e de conservá-lo indefinitivamente como seu horizonte de idealidade inesgotável; o objeto que é colocado como seu correlato pelos enunciados médicos dos séculos XVII ou XVIII não é idêntico ao objeto que se delineia através das sentenças jurídicas ou das medidas policiais (FOUCAULT, 2016, p. 39).

Em continuidade ao pensamento do filósofo, tem-se então a segunda hipótese que concerne ao conceito de FD, a qual diz respeito ao estilo. Aqui, Foucault (2016, p. 41) discorre que esse pressuposto está relacionado "a um certo caráter constante da enunciação". Para ele, a medicina não mais se organizava de maneira única, relacionada em moldes estanques, tradicionais e de cosmovisões heterogêneas. Segundo Foucault (2016, p. 42), o médico deixou de ser a centralidade dos significados porque "ao lado dele, fora dele, construíram-se massas documentárias, instrumentos de correlação e técnicas de análise que ele tem, certamente, de utilizar, mas que modificam, em relação ao doente, sua posição de sujeito observante". De um lado, há uma certa positividade nos elementos que descreveram o fato de a medicina se organizar de maneira singular, mas Foucault (2016, p. 42) logo a refuta quando diz: "seria preciso caracterizar e individualizar a coexistência desses enunciados dispersos e heterogêneos; o sistema que rege sua repartição, como se apoiam uns nos outros [...]".

A terceira hipótese formulada por Foucault (2016, p. 42) consiste em um questionamento: "não se poderiam estabelecer grupos de enunciados, determinando-lhes o sistema de conceitos permanentes e coerentes que aí se encontram em jogo?”. Para elucidar tal pergunta, ele faz uso do conceito de gramática em que sua continuidade se perpetuou durante séculos, organizada de modo a não sofrer severas modificações, e isso relacionado não no aspecto evolutivo, mas na cadeia de enunciados, que é o propósito de sua análise. Para ele, na verdade, o que seria relevante é que buscasse coerência não nos conceitos, "mas sua emergência simultânea ou sucessiva, em seu afastamento, na distância que os separa e, eventualmente, em sua incompatibilidade" (FOUCAULT, 2016, p. 43). Essa negação se dá pela alternância de sentidos, por aquilo que não é compatível ao objeto enunciativo. Teria, assim, de "analisar o jogo de seu aparecimento e de sua dispersão” (FOUCAULT, 2016, p. 43). Tal afirmação significa que Foucault pretende, com isso, estudar as regras de formação, o que tornou passível de ser considerado com objeto e, consequentemente, 
explicá-lo dentro de uma mesma cadeia enunciativa e como elas se modificaram. Os temas que fazem parte desse processo de dispersão e aparecimento não se constituem alheios a essa formulação. É preciso, então, admitir que "como a presença de uma estratégia determinada não individualiza um discurso, o objetivo será definir um sistema de relações entre diversas estratégias que seja capaz de dar conta de sua formação" (MACHADO, 1981, p. 106).

E, por último, na quarta hipótese, que se alia à terceira, Foucault (2016) discorre sobre a identidade e a persistência dos temas. E como quimera ilustrativa, o autor exemplifica as teorias do evolucionismo. Ele diz que tal temática possui suas necessidades e especificidades numa dada conjuntura discursiva, mas se pergunta se toda essa teoria não poderia ser conglomerada e se fazer aparecer como unidade. Segundo o referido autor, para se fazer isso, é preciso "transformar em saber discursivo o que fora esboçado como hipótese ou como exigência” (FOUCAULT, 2016, p. 44). No entanto, é preciso considerar no esboço teórico dos estudos arqueológicos, conforme assinala Machado (1981, p. 116), as "rupturas epistemológicas". Parafraseando o autor, conceber a história de maneira descontínua, não encarando a linearidade postulada por meio do tempo. Só assim é possível conceber as FDs como "um sistema de dispersão”. Foucault (2016, p. 47, grifo do autor) postula o seguinte:

No caso em que se puder descrever, entre um certo número de enunciados, semelhante sistema de dispersão, e no caso em que entre os objetos, os tipos de enunciação, os conceitos, as escolhas temáticas, se puder definir uma regularidade (uma ordem, correlações, posições e funcionamentos, transformações), diremos, por convenção, que se trata de uma formação discursiva.

E, para chegar ao conceito de FD, Foucault (2016, p. 47, grifo do autor) acha necessário, em seu estudo arqueológico, dizer que

Chamaremos de regras de formação as condições a que estão submetidos os elementos dessa repartição (objetos, modalidades de enunciação, conceitos, escolhas temáticas). As regras de formação são condições de existência (mas também de coexistência, de manutenção, de modificação e de desaparecimento) em uma repartição discursiva.

Então, o jogo de enunciados dispersos que se confluem uns nos outros, que se transformam sob a heterogeneidade, são para Foucault elementos que 
caracterizam e explicam as unidades enunciativas que são diversas, mas, ao mesmo tempo, são regidas por regras e sistematizações que implicam a necessidade de se fundamentar o conceito de FD. Com efeito, a empregabilidade do conceito de FD para Foucault é não a enxergar como se fosse a estrutura de um texto, mas "as noções de mobilidade, aproximação, o modo como o discurso isola temas e objetos, e se ajusta a conteúdos concretos" (ARAÚJO, 2020, p. 319). Para a arqueologia foucaultiana, o que importa, portanto, é que no limiar da $\mathrm{AD}$ se extrapolem questões em termos sintáticos e semânticos. Araújo (2020, p. 321) discorre ainda que, para Foucault, as verdades que se tornaram saberes sofrem transformações, e a dispersão, característica dessas relações, pode tornar-se ciência. As FDs são descontínuas, e, por isso, Foucault

[...] não está preocupado em estabelecer regras epistemológicas próprias a cada uma dessas ciências, e sim mostrar que, sempre que certo tipo de saber atinge o nível de ciência, de formalização e usa regras epistemológicas, isso só se dá a partir de uma formalização de uma formação discursiva (ARAÚJO, 2020, p. 330, grifo nosso).

Sendo assim, para Foucault, as questões relacionadas às ciências surgem em uma FD juntamente com o saber que se tornou uma verdade.

\section{FORMAÇÃO DISCURSIVA EM MAINGUENEAU}

Como fora postulado neste trabalho, a noção de FD foi primeiramente inaugurada por Michel Foucault e serviu como pressuposto teórico para outras disciplinas também interessadas em estudar o discurso. A AD de linha francesa também se apropriou desse conceito para explicar o fenômeno dos acontecimentos naturais, porém com uma particularidade que se distancia daquilo que Foucault, em seus estudos arqueológicos, postulou: o universo da língua. A linguística, ${ }^{3}$ dessa forma, como campo reconhecido dos estudos das múltiplas linguagens, concebeu a categoria FD para explicar os acontecimentos discursivos dos sujeitos também discursivos postos em interação.

Nesse ínterim, a AD foi entendida, de acordo com Charaudeau e Maingueneau (2008, p.43), como o estudo do discurso, tendo este como seu objeto

3 Leia-se linguística estrutural, geracional, sistêmico-funcional, cognitiva, entre tantas outras. 
de análise. Contudo, é preciso compreender que a noção de discurso encontra, em sua existência nos estudos da linguagem, variações conceituais devido ao fato de que tal concepção acerca do discurso obteve reformulações e reacentuações de acordo com a vertente teórico-metodológica na qual se filia. Pode-se dizer isso, por exemplo, a partir das proposições de Pêcheux, baseadas na filosofia de Althusser. Assim, inúmeras formas de se entender o discurso e, por consequência, as FDs emergiram para que, então, pudéssemos compreender como se dá a emergência de sentidos nessa perspectiva discursiva. Como pressuposto teórico, lançaremos mão da concepção de Dominique Maingueneau sobre FD para embasar este estudo e contribuir para discussões futuras no campo da AD de escola francesa.

Já se sabe que a concepção de discurso extrapola a noção de frase e sentença. Isto é, de acordo com o próprio Maingueneau (2015, p. 25-28), o discurso está para "além da frase; é uma forma de ação; é interativo; é contextualizado; é assumido por um sujeito; é regido por normas; é assumido no bojo de um interdiscurso; constrói socialmente o sentido".

Tais considerações significam que a unidade do discurso não é uma frase porque se estrutura com construtos de outra ordem semiótica. Em outras palavras, não é somente na modalidade oral e escrita que um discurso se manifesta. Ele pode surgir como uma categoria enunciativa que sequer precisa estar ancorada em palavras ou signos. O discurso, para Maingueneau (2015), é também uma forma de ação porque pressupõe que ele faz com que os indivíduos ajam no universo de sentidos, isto é, no mundo social. Ele é interativo na medida em que sempre está em constante interação com o Outro, significando para a AD não somente pessoas, mas categorias semióticas que emergem e constituem sentidos. Discurso também é contextualizado porque ele não aparece de forma linear. Essa linearidade não é mais compreendida nesse momento nos estudos acerca do discurso. Em outras palavras, ele surge numa dada conjuntura enunciativa cuja existência depende dos fatores que já foram e serão elencados nessa prévia introdução. Ademais, é regido por normas porque o uso da língua requer sistematização e regularidade. Dado o contexto sócio-histórico, o discurso obedece a essa circunstância, ou seja, as leis regadas de historicidade. O discurso também é assumido por um sujeito porque um dos fatores principais que regem a concepção dele, para a $\mathrm{AD}$, é a formação que se constrói socialmente. Não se pode falar em discurso sem que se esteja preconizado a "fonte de referência" (MAIN- 
GUENEAU, 2015, p. 27). O eu-discursivo está para alguém, inserido numa dada situação. E, por fim, está no interdiscurso pelo fato de um discurso não acontecer de maneira unívoca nem singular; é clivado por diversos outros discursos, atravessados e (re)significados, emergindo, então, inúmeros significados na cadeia discursiva.

Essas primeiras considerações, ainda que ordinárias, acerca do conceito de discurso servem para corroborar o que Maingueneau (2015, p. 65) explica sobre os analistas do discursivos: "devem categorizar os tipos de unidades com as quais eles próprios trabalham, unidades construídas em função das restrições e dos objetivos da pesquisa sobre o discurso".

Para conceituar uma FD, dentro dos limites da AD, Maingueneau (2008, p. 16, grifos do autor) nos diz que "não se pode dar um estatuto mais claro à noção de formação discursiva se não se leva em conta o conjunto de termos que designam as categorias sobre as quais a análise do discurso trabalha [...]", isto é, "as unidades tópicas e as unidades não tópicas". Sobre a primeira, Maingueneau (2008, 16-17, grifos do autor) diz que se refere a "unidades territoriais, que correspondem a espaços já 'pré-delineados' pelas práticas verbais", continua dizendo que "pode-se tratar de tipos de discurso relacionados a certos setores de atividades da sociedade: discurso administrativo, publicitário, político etc.", também reitera que "esses tipos englobam gêneros de discurso, entendidos como dispositivos sócio-históricos de comunicação, como instituições de palavras socialmente reconhecidas" e termina dizendo: "o tipo é um agrupamento de gêneros; todo gênero só o é porque pertence a um tipo”.

Nas formulações de Maingueneau (2008), o que está posto nessas considerações é que a heterogeneidade constitutiva do gênero discursivo preexiste a uma relação de subordinação, de dependência de um lugar institucionalizado. Para melhor clarificar, utilizaremos a unidade tópica “o discurso escolar” cujos gêneros do discurso que circulam nesse aparelho são diversos: o diário de classe, relatório, ofício etc., os quais pertencem a um mesmo tipo porque se trata de um agrupamento, isto é, de gêneros discursivos de uma mesma esfera. A partir dessas premissas, Maingueneau (2008, p. 17, grifos do autor) avança para "as unidades que poderíamos chamar de transversas, no sentido em que elas atravessam textos de múltiplos gêneros do discurso”. Podemos falar aqui de registros definidos a partir de três tipos de critérios: a) linguísticos; funcionais; comunicacionais. 
Sobre essas três categorias, Maingueneau (2008) discorre que a primeira tem como objetivo aparatos enunciativos; ${ }^{4}$ a segunda, critérios funcionais; ${ }^{5}$ e, por fim, a terceira, ${ }^{6}$ uma mistura entre comunicacionais e linguísticos.

Para, enfim, adentrarmos no conceito de FD, fez-se necessário conceituar as unidades tópicas, uma vez que

Só pode haver análise do discurso se ela se apoia em unidades tópicas, mas elas não podem dar conta, sozinhas, do funcionamento do discurso, que é atravessado por uma falha constitutiva: o sentido se constrói no interior das fronteiras, mas mobilizando elementos que estão fora delas (MAINGUENEAU, 2015, p. 81).

Isso ocorre porque as unidades não tópicas também constituem as FDs. Entretanto, o autor alerta que

[...] o analista, em função de sua pesquisa, dá forma a uma configuração original. Isso permite o afastamento de uma concepção "especular" da construção do corpus. Frequentemente, com efeito, considera-se o corpus como uma espécie de condensado, de espelho, de conjunto de textos, cuja unidade seria dada de antemão; daí as discussões acirradas para saber se o corpus é suficientemente "representativo" (MAINGUENEAU, 2008, p. 22, grifos do autor).

A questão da problemática do corpus é de fundamental importância para a $\mathrm{AD}$, pois permite que se considerem noções sobre as FDs não somente em relação ao que se pesquisa, mas também no que concerne aos rumos da pesquisa que o analista se dispõe a fazer.

Nesse sentido, Maingueneau (2008, p. 22) nos mostra, em seus estudos, que as FDs podem ser "unifocais" e "plurifocais". Tais conceitos consistem nos caminhos da pesquisa e em que entendimento se está fazendo do corpus escolhido para realizar a análise. A primeira, como o próprio nome já diz, possui um foco único de análise, e a preocupação do autor não está nela, mas sim na segunda, pois esta "traz para primeiro plano as interrogações que a pesquisa

4 E. Benveniste (1993) estabeleceu entre "história" e "discurso".

5 Os critérios funcionais são conhecidos como o célebre esquema das seis funções de Jakobson, que preconiza o uso da linguagem com uma intenção.

6 Unidades definidas por uma combinação de traços linguísticos e comunicacionais que tem como premissa "o para que" serve um determinado texto (MAINGUENEAU, 2008, p. 18). 
produz" (MAINGUENEAU, 2008, p. 22). Aquele que pesquisa sobre o prisma das FDs plurifocais precisa fazer com que a escolha do corpus não se constitua de forma aleatória para que o rigor metodológico da pesquisa se mantenha, pois há o risco de o caminho escolhido para determinada análise desenhar outro porque uma FD forja-se com textos heterogêneos.

$\mathrm{O}$ intuito de se fazer pesquisa em $\mathrm{AD}$ é romper fronteiras e atravessar discursos. A motivação de se olhar um dado fenômeno sob o crivo discursivo é se coadunar com as relações do interdiscurso, atravessar significados, tornar possível o surgimento de outros e mapear a função deles, e, com o nome de "percurso", Maingueneau (2008) faz jus exatamente a isso. Para o autor, a maneira como nos debruçaremos em um determinado tipo de análise é um exercício de transpor os limites dados, interpretações relativas, sobretudo confrontar as próprias convicções do analista. E mesmo assim "há um conjunto de princípios, de técnicas que regulam esse tipo de atividade hermenêutica" (MAINGUENEAU, 2008, p. 24).

Restringir a análise do discurso apenas às unidades tópicas seria denegar a realidade do discurso, que é relacionamento permanente do discurso com o interdiscurso: este último "trabalha" o discurso, que em retorno o redistribui perpetuamente (MAINGUENEAU, 2008, p. 25).

Maingueneau (2015) nos lança ainda mais dois (mas não únicos) conceitos de FD: temática e construída a partir de entidades. ${ }^{7}$ A primeira diz respeito a "organizá-la não a partir de uma instância produtora, mas a partir de um tema (do que se fala?) que toma habitualmente a forma de uma expressão nominal com o artigo definido: 'a droga', 'a eutanásia', 'a guerra no Afeganistão”” (MAINGUENEAU, 2015, p. 86). E continua: “não é estudar o referente correspondente [...], mas no interior de certos limites espaciais e temporais que convém definir - os enunciados que falam dele" (MAINGUENEAU, 2015, p. 86). Já uma FD construída a partir de uma entidade "centra-se em humanos ou seres dotados de propriedades antropomórficas [...] uma instituição - o exército, um partido político, um momento, um lugar" (MAINGUENEAU, 2015, p. 87 , grifos do autor).

7 Vale ressaltar que Maingueneau (2008, p. 86-90) conceitua outros tipos de FD. Segundo o autor, as FDs podem ocorrer por meio de acontecimentos ao longo do tempo: FDs-cenários preconizam temas centrais de uma dada informação e FDs-nós referem-se a um tema recorrente de uma comunidade. 
Por fim, para ilustrar as FDs construídas por entidades, o autor diz que "trata-se, para a análise do discurso, de apreender as entidades por meio de funcionamentos discursivos, e não como a expressão de realidades que estariam acima, fora da linguagem" (MAINGUENEAU, 2015, p. 87).

\section{CONSIDERAÇÕES FINAIS}

O que se pretendeu com o presente trabalho foi realizar uma análise comparativa dos conceitos de FD estabelecidos por Michel Foucault e Dominique Maingueneau, e localizar, em seus postulados, interconexões nos embates teórico-metodológicos, além de descrever como esses dois autores, inseridos em campos epistemológicos diferentes, apresentaram a FD, a qual é tão difundida nos estudos sobre a linguagem atualmente.

Nossa contribuição consiste em mostrar a importância do conceito de FD para os estudos da linguagem, de modo a permitir que tal aporte teórico seja de fundamental importância para aqueles que se dedicam a estudar os fenômenos da linguagem no campo da AD de linha francesa, uma vez que, se há discursos, há FDs. Não é possível desatrelar um fenômeno do outro, pois eles acontecem numa relação de subordinação, e, por isso, seu entendimento, sua conceituação e compreensão são necessários para os analistas do discurso. A partir de 1969, esse conceito veio a ser transformado, atravessando diferentes concepções das áreas do conhecimento.

Num prospecto de tempo de 1969 a 2015, as ciências da filosofia de Foucault e da linguística discursiva de Maingueneau tiveram seus construtos relegados a um mesmo conceito, mas com vieses diferenciados. Nosso intuito também foi apresentar, ainda de maneira sucinta, outros momentos em que o conceito de FD foi utilizado e organizou o pensamento heuristicamente no limiar das décadas de 1970 e 1980. Pudemos, então, descrever a maneira como tal conceito foi se engendrando e se constituindo como categoria de análise empírica. Se Foucault conceituou as FDs como um campo de dispersão, de descontinuidades e de rupturas, percebemos, paradoxalmente, em Maingueneau, que as FDs são diversas e estabelecidas com o aparato da linguagem como processo de constituição. A língua é o construto para Maingueneau e, para Foucault, é a busca de um novo campo do saber em relação ao conceito de FDs. Em outros termos, Foucault buscou entender com seus estudos arqueológicos como uma determinada categoria tornou-se uma verdade. 
Ademais, ao longo deste artigo, mostramos que, no decorrer dessa temporalidade demarcada, outros conceitos como ideologia e historicidade fizeram parte do entendimento, sobretudo na conceituação das FDs. Sendo assim, como o próprio título deste trabalho sugere, apreender a noção de um conceito em duas perspectivas diferentes não é pôr em confronto, em colisão, as ideias, senão teríamos de seguir outra ordem metodológica.

Outrossim, estabelecemos como ocorre a representação da realidade postulada pelos dois autores e apontamos que, em ambas as conceituações, o enunciado não é neutro e que a linguagem, na perspectiva da $\mathrm{AD}$, está ligada tanto aos efeitos de sentido quanto às questões sociais. Isso ocorre porque a $\mathrm{AD}$ preconiza três eixos discursivos: produção, circulação e recepção. A AD considera o discurso como um fato social e deixa de ser uma entidade abstrata, e, para apreendê-lo, é preciso que o sujeito possua competência discursiva, o que significa dizer que o indivíduo necessita da competência de ordem discursiva, textual, pragmática, social e linguística, e, somente dessa forma, podemos considerar o discurso como um ato de linguagem, que remete ao contexto e à memória discursiva.

Assim, o sujeito, ao se expressar por meio dos discursos, insere-se nas relações de sentido porque o objetivo comunicativo-discursivo o leva a fazer algo esperado pelo enunciador de acordo com a FD, criando relações intersubjetivas que significam a relação entre sujeitos a qual envolve pensamentos, comportamentos, ideologias e crenças, e tem como premissa a não intencionalidade, pois a produção de um discurso não ocorre de maneira deliberada. A interação sobre os sujeitos como mediadores do discurso faz com que eles sejam construtores do conhecimento a partir das competências discursivas de cada falante.

Dessa forma, a FD vai se construindo à medida que o sujeito interage com o interlocutor, de modo a exercer um poder cuja inscrição se dá com o discurso direcionado a exercer uma função sobre o outro. Poder entendido como relação com o outro, desempenhando uma função estratégica com o objetivo de persuadir o outro, mudar o discurso do outro. Nesse aspecto, as FDs têm como objetivo a compreensão das buscas das contradições, isto é, buscar o resultado da formação ideológica. O objetivo deste artigo foi mostrar como o conceito de FD, cunhado primeiramente por Michel Foucault, dentro do campo da filosofia, e incorporado, posteriormente, pela linguística pós-estruturalista, por Dominique Maingueneau, quando este insere a linguagem/língua como um 
pressuposto para a existência de uma FD. O entendimento desse fenômeno da linguagem está longe de ser considerado pronto e acabado. Como a língua está em constante movimento, a linguagem, vai se (re)significando a todo instante.

Se, para Foucault, é preciso delimitar o objeto ao qual o discurso está circunscrito, isto é, perceber nele as (ir)regularidades, as dispersões e as descontinuidades, e, dessa forma, desvelar o funcionamento das regras de formação, para Maingueneau, no entanto, é preciso considerar a língua e os fatores exteriores a ela, isto é, a sócio-história, de modo que se possam apreender os gestos de sentido contidos numa dada FD. Assim, Foucault tematiza que é preciso compreender todas as imbricações que cerceiam um dado objeto. Para o autor, nem tudo diz respeito à confluência do discurso e das FDs. E, por isso mesmo, A arqueologia do saber (FOUCAULT, 2016) caracteriza-se não por um livro que discorre sobre teorias, mas um percurso metodológico para se compreender como se dá a descontinuidade que rege tanto o discurso quanto a FD. Maingueneau $(2008,2015)$ preconiza a língua como materialidade para o acontecimento de uma FD, conforme já assinalamos.

\section{The concept of discursive formation based on the studies of Dominique Maingueneau and Michel Foucault: a comparative analysis}

\section{Abstract}

Conceiving the relationship between language and discourse as mediators of man's social relations requires a look at how such assumptions (the interaction between individuals with language and exteriority) convey meanings in the socio-historical context. Thus, this article aims to analyze and understand, comparatively, how the understanding of discursive formation is postulated in the understanding of Michel Foucault (1969) and Dominique Maingueneau (2008, 2015). The purpose of this paper is not, under any hypothesis, to superimpose one concept to another, but to establish a dialogue between the two scholars, situated in different contexts, but with the same concern: the discursive studies.

\section{Keywords}

Foucault. Discursive formation. Maingueneau. 


\section{REFERÊNCIAS}

ARAÚJO, I. L. Formação discursiva como conceito chave para a arqueogenealogia de Foucault. In: BARONAS, R. L. (org.). Análise de discurso: apontamentos para uma história da noção-conceito de formação discursiva. Araraquara: Letraria, 2020. p. 318-360.

BARONAS, R. L. Ainda sobre formação discursiva em Pêcheux e em Foucault. In: BARONAS, R. L. (org.). Análise de discurso: apontamentos para uma história da noção-conceito de formação discursiva. Araraquara: Letraria, 2020. p. 394-410.

BENVENISTE, E. Problemas de linguística geral I. Campinas: Pontes, 1993.

BRANDÃO, H. H. N. Introdução à análise do discurso. Campinas: Editora da Unicamp, 1994.

CHARAUDEAU, P.; MAINGUENEAU, D. Dicionário de análise do discurso. São Paulo: Contexto, 2008.

COLOMBAT, B.; FOURNIER, J.-M.; PEUCH, C. Uma história das ideias linguísticas. Tradução Jaqueline Léon e Marli Quadros Leite. São Paulo: Contexto, 2017.

COURTINE, J.-J. Análise do discurso político: o discurso comunista endereçado aos cristãos. São Carlos: EdUFScar, 2014.

FOUCAULT, M. A arqueologia do saber. Tradução Luiz Felipe Baeta Neves. 8. ed. Rio de Janeiro: Forense Universitária, 2016.

GIACOMONI, M. P.; VARGAS, A. Z. Foucault, a arqueologia do saber e formação discursiva. Veredas on-line - análise do discurso - 2, Juiz de Fora, p. 119-129, 2011. Disponível em: https:/www.ufjf.br/revistaveredas/files/2010/04/artigo-09.pdf. Acesso em: 5 abr. 2021.

INDURSKY, F. Da interpelação à falha no ritual: a trajetória teórica da noção de formação discursiva. In: BARONAS, R. L. (org.). Análise de discurso: apontamentos para uma história da noção-conceito de formação discursiva. Araraquara: Letraria, 2020. p. 300-317.

LACAN, J. Écrits. Paris: Seuil, 1966.

MACHADO, R. Ciência e saber: a trajetória da arqueologia de Foucault. Rio de Janeiro: Edições Graal, 1981.

MAINGUENEAU, D. Novas tendências em análise do discurso. Tradução Freda Indursky. Revisão dos originais da tradução Solange Maria Ledda Gallo e Maria da Glória de Deus Vieira de Morais. 3. ed. Campinas: Pontes, 1997.

MAINGUENEAU, D. Cenas da enunciação. Organização Sírio Possenti e Maria Cecília Pérez de Souza-e-Silva. São Paulo: Parábola, 2008. 
MAINGUENEAU, D. Discurso e análise do discurso. Tradução Sírio Possenti. São Paulo: Parábola, 2015.

ORLANDI, E. P. Análise de discurso: princípios e procedimentos. Campinas: Pontes, 2009.

VOSS DOS SANTOS, J. Especificidades do discurso e das formações discursivas para Michel Foucault: práticas discursivas e não discursivas. In: BARONAS, R. L. (org.). Análise de discurso: apontamentos para uma história da noção-conceito de formação discursiva. Araraquara: Letraria, 2020. p. 337-360. 